Ethiopian Journal of Environmental Studies \& Management 7 Suppl.: 890 - 901, 2014.

ISSN:1998-0507

doi: http://dx.doi.org/10.4314/ejesm.v7i2.9S

Submitted: October 14, 2014

Accepted: December 04, 2014

\title{
SOCIOECONOMIC IMPACT ASSESSMENT OF INTEGRATED INDUSTRIAL ESTATE PANTNAGAR, INDIA
}

\author{
*ALI SEID MOHAMMED, ${ }^{1}$ UMA MELKANIA² AND B. N. KUMAR ${ }^{3}$ \\ $1_{*}$ Department of Biology, Bahir Dar University, Ethiopia \\ ${ }^{2 \&}$ G.B. Pant University of Agriculture \& Technology, Pantnagar 263 145, U.S. Nagar
}

(Uttarakhand), India

\begin{abstract}
A Socioeconomic Impact Assessment (SIA) of Integrated Industrial Estate (IIE)-SIDCUL Pantnagar was completed in March 2010 after three years of its establishment, based on primary and secondary data collection (survey data, company's reports, websites, library and other related documents). The 276 industries established in the area have created jobs for a total of 27,812 (35\% of the district industrial workers) individuals. The general public attitude $172.16 \%$ positive), impact distribution (70.56\% middle class) and the general wellbeing of society around are significantly good. However, local people also voiced their apprehensions about water quality and quantity, health problems, power interruption. Population of Rudrapur town will be more than double in 20 years. While, house and land values have increased 2 to 3 times, labor force has become farming constraint. These plus the cultural prestige are forcing the local people to sell their farm lands for house building and/or daughters' marital expenditure (dowry). The rapid urbanization, increasing land value and discharge of waste are found to be derivers of the socioeconomic changes. Based on the results some mitigation measures to reduce the pressures are suggested.
\end{abstract}

Key Words: SIA, Industrial Estate, Pantnagar, India

\section{Introduction}

Economic development is the result of the interaction between natural resources and technology supported by and designed for people. Therefore, it is rightly said that all human activity, be it economic, social or anything else, are essentially directed at satisfying "needs" and "wants" of man through "altering" and "using" environmental resources. Worldwide current policy shifts are tending towards eliminating or minimizing the continuing trends of environmental degradation. Socioeconomic Impact Assessment (SIA) is a valuable tool to put into effect a key sustainable development principle i.e.: "human beings are at the centre of development" (Asian Development Bank India, 2002).

Because of economic advancement and increasing urban growth, environmental problems in Asia are many and they have attracted attention around the world (Marafa, 2002). These problems are a result of growing population, economic pressures and development processes. In the urban areas of Asia and elsewhere in the world, rapid urbanization affects the state of the environment, and proposed solutions to

*Corresponding Author: Ali Seid 890

Email: alinabiot@yahoo.com 
perceived environmental problems have become an integral part of the political and economic debate.

Consideration of the social impact of development project generally was until recently not an adjunct of EIAs. It would appear to be very much so even today in India, where more emphasis continues to be placed on the biophysical environment. Nonetheless, social impact analysis is gaining ground and momentum. But even then it poses special problems which make it far more than a methodological shadow of EIA. Socioeconomic Impact Assessment (SIA) represents a novel and far more complex domain.

International Association of Impact Assessment (IAIA, 1999) defined SIA to include the processes of analyzing, monitoring and managing the intended and unintended social consequences, both positive and negative; of planned interventions (policies, programmers, plans, projects) and any social change processes invoked by those interventions. Its primary purpose is to bring about a more sustainable and equitable biophysical and human environment. While SIA tends to focus on the avoidance of adverse impacts, SIA also provides a forum for planning how to maximize the beneficial impacts of a proposed development.

Communities living in rural areas in general and in the developing countries in particular contend with a number of socioeconomic challenges due industrialization and lack of awerness (Kahn, 2000). Some of the socio-economic challenges faced in rural areas include: unemployment, poor housing, ill health, food insecurity, lack of access to land for cultivation, and illiteracy (FAO, 2002; Grinspun, 2003). Furthermore, in many countries, the poverty gap between urban and rural areas has been widening (Khan, 2000) with the former attracting more investments in industries.

Three districts in the plains area of Utrakhand, namely, Dehradun, Haridwar, and Udham Singh Nagar (the study area) together account for $82 \%$ of the workers employed in $40 \%$ of the total number registered units in the State. Largest numbers of industrial workers are concentrated in Haridwar, followed by Udham Singh Nagar. Haridwar is the industrial hub of the State, and houses the largest industrial estate of the State. Some more Industrial Estates are proposed for this district Udham Singh Nagar (Rudrapur and Pant Nagar in particular) is fast emerging with industrialization of the district.

To ensure that development is managed so that it is both sustainable and contributes to industrial and community stability, major land use shifts have required the proper assessment and understanding of community interests. It is against the foregoing background that this SIA was started. Thus, the objectives of the study objective were: to assess communities' needs and expectations; to identifying people perception and attitude towards the project development activities; and to describe both negative and positive socio-economic consequences IIE- Pantnagar development activities.

\section{Problem Statements and Objectives}

The above mentioned industrial estates were established without impact assessment study, IIE Pantnagar one of which made without SIA for the reason that it had fallen in the Land of G.B. Pant University of Agriculture and Technology (GBPUAT) which is part of government land (GBPUAT staffs personal communication For this reason and after conducting reconnaissance survey we hypothesized that the local communities would have been receiving both positive and negative socioeconomic impacts due to the project. Thus, our research questions were: 1) what are the impacts of 
the IIE-Pantnagar on the local people? 2) Were there symmetrical the distribution (up and down stream) of socioeconomic impacts? 3) Was there good attitude of local people towards the project? and 4) are there negative impacts that need mitigation measures?

Thus, the major objectives of the study were to: assess communities' needs and expectations; identifying people perception and attitude towards the project; and to describe both negative and positive socioeconomic consequences IIE- Pantnagar development activities.

\section{Description of the Project}

Carved out of Uttar Pradesh in 2000, the Uttarakhand (the then Uttranchal) State administration embarked on a comprehensive programme of driving industrial growth in the state. In line with the above vision of economic development of Uttarakhand, state of the art Integrated Industrial Estate (IIE) is envisaged at Sitarganj in Udham Singh Nagar district by State Infrastructure \& Industrial Development Corporation of Uttarakhand Limited (SIDCUL), which is the nodal agency for promoting industrial development in the state.

According to (UUDP, 2007) the Government of India has announced a Special Package on January 7, 2003, where under $100 \%$ outright Central Excise exemption, $100 \%$ Income Tax exemption, for 5 years and at 25/30 percent for 5 years thereafter, and 15 percent capital subsidy, subject to a ceiling Rupees 3,000,000 have been provided for certain categories of industries, together with incentives pertaining to certain existing schemes of Ministries of Industry, Commerce, SSI and Food Processing, etc. Following this announcement about 300 industrial units with an investment of more than Rs. 50 Billion have expressed their desire to set up industries in the State. Two large-scale and one relatively smaller Integrated Industrial Estates have been identified: among these three, the largest one is located in Pantnagar, near Rudrapur (about 33,000 acres), the second largest in the BHEL campus in Haridwar (about 1500 acre) and the relatively smaller one at Saggadi Growth Centre.

According to GHK Consulting, UK (2007) in 2006 Uttrakhand (the then Uttaranchal) has 300 hundred registered large and medium scale industrial units in operation. Total number of workers employed by these units was 41,777 in 2005 . These industrial units, not large in number, and are concentrated mostly in the plains.

\section{Materials and Methods \\ Description of Study Area}

The Udham Singh Nagar district is situated at 28 degree south east, 30 degree North latitude, 78 degree and 81 degree east longitude (Figure 1) and altitude is about 550 meter above sea level. The total district is Tarai and water is available at the depth of 10 to 20 meters. 


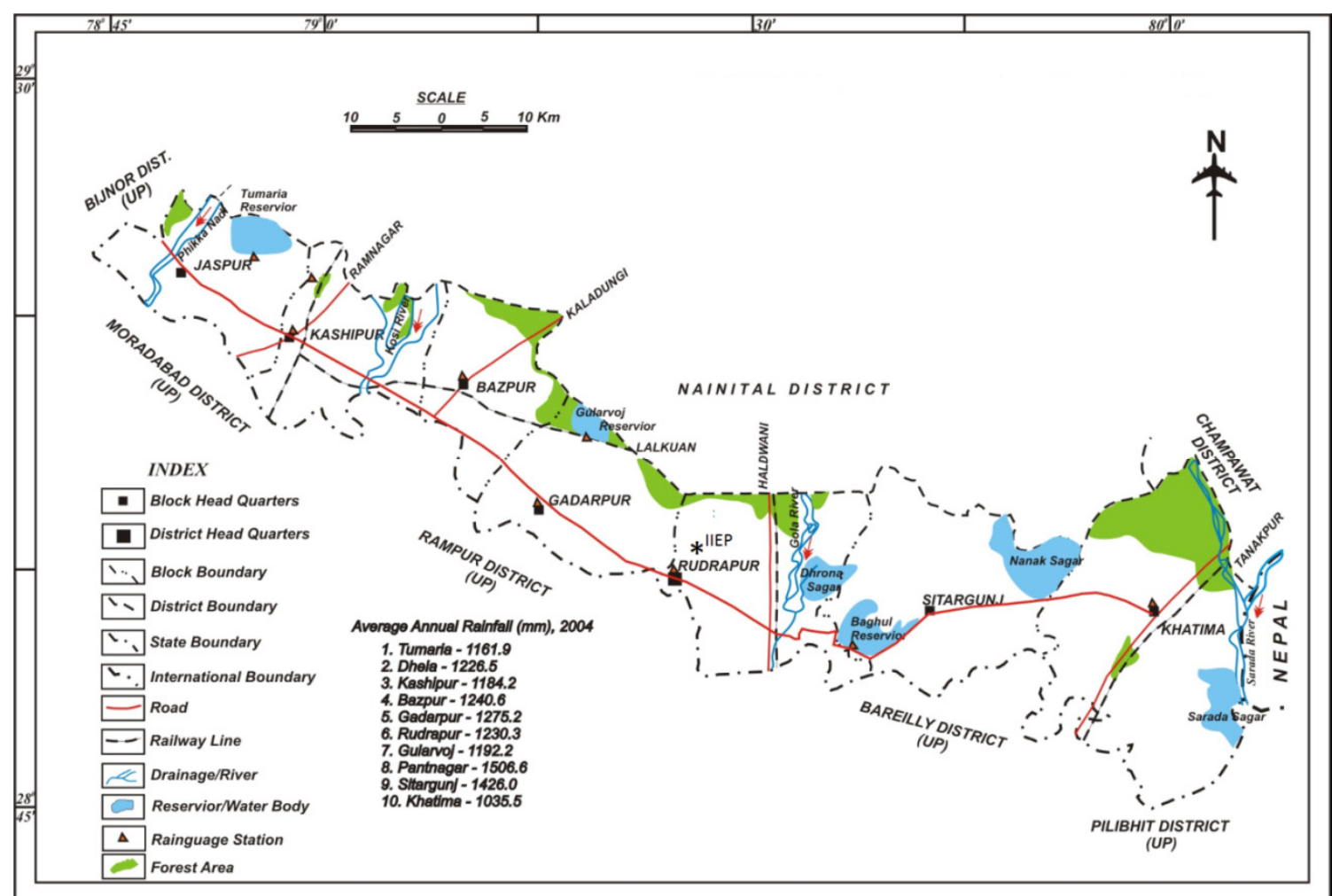

Figure 2: Location Study Site $\left(^{*}\right)$ in the Map of District Udham Singh Nagar (MoWR, 2009)

\section{Data Collection}

Data were collected mainly from two sources: from people living in the nearby villages and from local officials. The method applied for the data collection comprised of semi-structured questionnaire and in-depth interviews designed based on Arora and Tiwari (2007) and Edwards (2009). First, a total of 120 informants from 12 villages within $5 \mathrm{~km}$ radius participated. Villages were visited several times at different days to conduct the survey and make observations. Second, focused group discussions (FGDs) were conducted in randomly selected four villages. Each FGDs comprised different groups of Panchayat Members (Village leaders), school teachers, political leaders, leaders of informal/formal organisations, representatives of different castes; communities, gender and occupations. Each of the FGDs was very extensive lasting for at least 1-2 hours of duration.

Stratified random sampling technique was used to represent villagers from all sides. People mainstay was used for stratification and random numbers were used to select households. Descriptive data analysis was done by excel and analysis of variance done by SPSS software.

\section{Results and Discussion}

The area is an agriculture prime area with at least $70 \%$ of the population relying on farming and related business for livelihood and famous for its premium quality rice. Table 1 shows the details of development blocks and population as of census 2001 . 
Table 1: Details of Developmental Blocks and tehsils (sub-blocks) of Udham Singh Nagar District

\begin{tabular}{llllllll}
\hline No & $\begin{array}{l}\text { Name of } \\
\text { the Block }\end{array}$ & $\begin{array}{l}\text { Area } \\
\left(\mathrm{Km}^{2}\right)\end{array}$ & $\begin{array}{l}\text { Name of } \\
\text { Tehsil }\end{array}$ & $\begin{array}{l}\text { Population } \\
\text { Census 2001 }\end{array}$ & Villages & \\
\cline { 7 - 8 } & Jaspur & 232 & Jaspur & 98279 & 100 & 5 & \\
\hline 1 & Kashipur & 185 & Kashipur & 86831 & 75 & 2 & 105 \\
2 & Bazpur & 286 & Bazpur & 102143 & 113 & 3 & 77 \\
3 & Gadarpur & 233 & Gadarpur & 104201 & 69 & - & 116 \\
4 & Rudrpur & 307 & Rudrpur & 109730 & 90 & - & 69 \\
5 & Sitargunj & 325 & Sitargunj & 146584 & 120 & 2 & 90 \\
6 & Khatima & 324 & Khatima & 161291 & 89 & 1 & 122 \\
7 & 1103 & & & 23541 & & 90 \\
Forests & 60 & & & 403014 & & \\
Urban & & & & 1235614 & 656 & 13 & 669 \\
\hline
\end{tabular}

Source: District statistical Diary, 2005, district Udham Singh Nagar

\section{Demography}

Based on the 2001 India census, Rudrapur had a population of 88,720 . Males constitute $53 \%$ of the population and females $47 \%$. Rudrapur has an average literacy rate of $55 \%$, lower than the national average of 59.5\%: male literacy is 62\%, and female literacy is $47 \%$. In Rudrapur, $16 \%$ of the population is under 6 years of age (Rao, and Nandy, 2001). According to GHK Consulting, (2007) Rudrapur, the nearest urban center, already achieved high population growth rate of $38.7 \%$ in the $1980 \mathrm{~s}$ and grew further to $43 \%$ in the $1990 \mathrm{~s}$. However, this trend was changed in $1^{\text {st }}$ decade of the new century in to $31 \%$. The decline in population growth rate from 2001 did not however indicate that Rudrapur's population growth rate will stabilize at that level. As the economy of the town grows, it will attract more migrant laborers, which will increase the population growth rate. At the present growth rate of $3-4 \%$ per annum, given the 2001 initial population it will reach 180,000 by the year 2020 .

\section{Socio Economic Impacts}

Public Perception and Attitude towards the Project

The industrial estate was viewed by the people to be desirable in hastening the development of the two local municipalities (Rudrapur and Lalquan) and the nation in terms of improved income and employment opportunities. The questionnaire survey result showed that a significant proportion of people (72.16 percent) living around the project have positive attitude (Table 2). The general public attitude analysis also shows highly significant positive volubility and public affection.

Table 2: Pulled Percentage Values of Attitude Assessment

\begin{tabular}{llllll}
\hline Item & Positive & Negative & Neutral & Response rate & F value \\
\hline Valubility & $81.19^{* *}$ & 16.83 & 1.98 & 96.19 & $.3616657 \mathrm{E}+02$ \\
Community impact & 68.75 & 19.79 & 11.46 & 91.43 & $.4816605 \mathrm{E}+01$ \\
Lack of opposition group & 60.20 & 12.24 & 27.55 & 93.33 & $.1256559 \mathrm{E}+01$ \\
Importance to the community & 63.54 & 31.25 & 5.21 & 91.43 & $.5155259 \mathrm{E}-06$ \\
Zeal & $87.13^{* *}$ & 12.87 & 0.00 & 96.19 & $.8312248 \mathrm{E}+02$ \\
Average & $72.16^{* *}$ & 18.60 & 9.24 & 93.71 & $.5458685 \mathrm{E}+02$ \\
\hline
\end{tabular}

$* *$ Highly significant at $(0.01)$ and $n s=$ not significant 


\section{Impact on Social Group}

Villages found in the southern side of the project site (100\%) said there is no emerging social group. Though 100 percent of respondents from the southern villages agreed that there is no new social group, but it is not statistically significant because more respondents of the Villages in the Northern and Western side are not experiencing more social transformation due to township which is more towards Rudrapur.

Table 3: Public Response Regarding Emergence New Social Group and Existence of Conflicting Groups

\begin{tabular}{llll}
\hline $\begin{array}{l}\text { Item No. / Villages } \\
\text { 7. Immergence of new group }\end{array}$ & Positive & Negative & F value \\
\hline Villages in the North & 46.67 & 53.33 & \\
Villages in the West & 39.39 & 60.61 & \\
Villages in the South & 0.00 & 100.00 & \\
Average & 19.35 & 80.65 & $.4323229 \mathrm{E}+01 \mathrm{~ns}$ \\
8. Conflicting group & & & \\
Villages in the North & 19.35 & 80.65 & \\
Villages in the West & 0.00 & 100.00 & \\
Villages in the South & 8.33 & 91.67 & \\
Average & 9.23 & $90.77 * *$ & $.1058799 \mathrm{E}+03 * *$ \\
\hline$* *$ Hight
\end{tabular}

** Highly significant at $(0.01)$ and ns= not significant

As shown in the table above, the significant proportion of respondents also mentioned that there is no conflicting group in the villages of IIE Pantnagar vicinities. This means, the diversity of the native people could help to absorb the limited number of new comers from other states or the tolerant culture of Indian would explain it.

\section{Impact Distribution among Economic Classes}

Informants' response in relation to impact distribution is asymmetrical and not well differentiated (Table 4). As the middle class is significantly dominant group, the southern villages suggest that both positive and negative impacts (good and the bad) are more on the middle class. However, villages in the North and West have opposing views. As it is common psychological response people are expected to say they lost more and received less, the non significant distribution of responses would tell us there is no much difference in impact distribution.

Table 4: Impact distribution on different socioeconomic classes

\begin{tabular}{|c|c|c|c|c|}
\hline \multicolumn{5}{|c|}{ Dominant Economic Group } \\
\hline Item & & & & value \\
\hline Villages & Rich & Medium & Poor & (ANOVA) \\
\hline Villages in the North & 19.35 & 61.29 & 19.35 & \\
\hline Villages in the West & 6.25 & 62.50 & 31.25 & \\
\hline Villages in the South & 9.09 & 87.88 & 3.03 & \\
\hline Average & 11.57 & $70.56^{* *}$ & 17.88 & $.1993637 \mathrm{E}+02$ \\
\hline
\end{tabular}




\section{Health Impacts}

Health related assessment questionnaire response is generally negative (Table 5). The major health complaints are breathing problems (all villages) plus skin diseases in the southern side (downstream). While some informants from the southern side indicated that sometimes, their domestic animals have died drinking contaminated water. Most people said "the river water is completely useless." However, they had been using it for irrigation purposes. Though it was not in the scope of our study a question was raised as to 'why they did so?' during our FGD. Their response was "we do not have other option."

Table 5: Health Related Issues due to IIE Pantnagar

\begin{tabular}{lllll}
\hline Item & $\begin{array}{l}\text { Highly } \\
\text { Negative }\end{array}$ & $\begin{array}{l}\text { Moderately } \\
\text { Negative }\end{array}$ & Positive & F value \\
\hline 1. Health problem & $66.85^{*}$ & 15.21 & 17.94 & $.1092640 \mathrm{E}+02$ \\
$\begin{array}{l}\text { 2. Specific Diseases } \\
\text { mentioned }\end{array}$ & & 49.44 & 50.56 & $.4871206 \mathrm{E}-02 \mathrm{~ns}$ \\
\hline
\end{tabular}

* Significant at (0.05) and ns= not significant

\section{Impact on Social Organizations}

Communities around the vicinity of the IIE indicated that there is significant change on their village level social organizations (Table 6). For most of the villages studied their proximity to Rudrapur town had changed their way of life due to growth of the town.

Table 6: Summary of Responses Regarding Village Level Social Organizations

\begin{tabular}{lllll}
\hline Item & $\begin{array}{l}\text { Positive } \\
(\%)\end{array}$ & $\begin{array}{l}\text { Negative } \\
(\%)\end{array}$ & $\begin{array}{l}\text { Highly } \\
\text { negative } \\
(\%)\end{array}$ & F Value \\
\hline Social Organization Change & 19.77 & 31.40 & $48.83^{* *}$ & $.1551668 \mathrm{E}+02$ \\
Effect of Change & 24.03 & 13.01 & $62.96^{*}$ & $.6085888 \mathrm{E}+01$ \\
Social Environment & $62.96^{* *}$ & 13.01 & 24.03 & $.7751263 \mathrm{E}+02$ \\
Security & 8.56 & 31.37 & $60.07 * *$ & $.2403683 \mathrm{E}+02$ \\
Absence of Hazard risk & $70.53^{* *}$ & 29.47 & 0.00 & $.1297584 \mathrm{E}+02$ \\
\hline
\end{tabular}

** Highly significant at (0.01), * Significant at (0.05)

Though, it can be considered as direct consequence of urbanization, it is also due to array of external variables associated with population and economic growth due to industrialization. Form responses to open ended questioners few people indicated that there is a tendency of nuclear family formation and community fragmentation do to urbanization and so called 'modern way of life'.

\section{Impact on Basic Natural Resources (Soils and Water)}

The summery of closed-ended questionnaire come up with proportional reply for both negative and positive impact on water and soil resources. The open-ended responses, however, indicated that there is asymmetrical impact on these resources. Respondent from the southern village (downstream) indicated the existence of great water pollution and as a result 'Beygul' River has become useless except for irrigation. 
While respondents from the western side claim regarding the deepening of ground water table, key informants from villages indicated that a number of farmers were fooled and sold their top fertile soils during the construction phase of IIE. The cost of 100 $\mathrm{cm}$, one hectare top soil was 100,000 Rupees. But, the claim of the two sides diluted by the lack of impact on the north, for most people living in northern side are people working in government jobs (not farmers).

It was just as an exercise that farmers from away from the town were asked: would you like to sell your land for building? On every face there was a look saying something like: "are you fool?" or "what a silly question!" Then the sole answer was "Of course, I will sell it, who wouldn't?" , and some of add " I can buy a larger plot somewhere else, build a house and do so many things that I was not able to do it before.

Economic Impacts

Employment

The industrial estate provides employment for 27,812 workers in the fully established industries and a lot more in self established service giving sectors of mainly in the immediate vicinity, Rudrapur and Lalkuan towns. The proportion of employee from the state (18925) is more than twice those from other states (8887) (Figure 2).

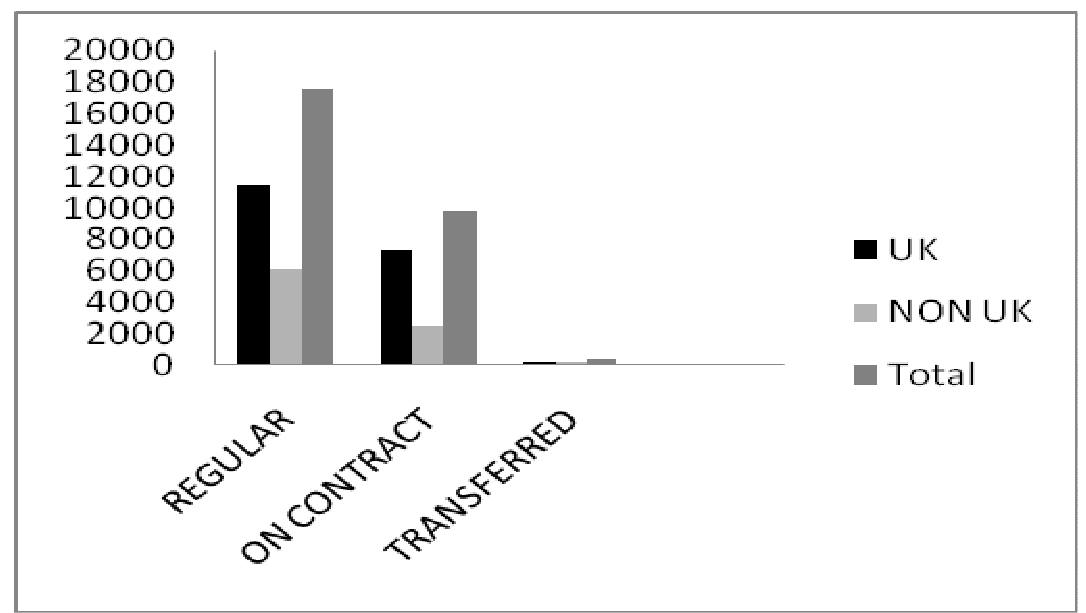

Figure 2: Histogram Showing the Proportion of Employee based on Capacities Classes

Indeed the SIDCUL management has made a good effort to insure that industries gave more chance of employment for local residents. Another fact is that, so far only limited number of new major labor intensive industries entered the area since the start of its operation in 2004. They are also highly capital and/or technology intensive. These can be another explanation for why people view employment is a weak impact or said that many of the workers are outsiders. In this regard, the problem seems beyond the control of SIDCUL management, since the decision for locating an industry in the estate is decided by the investors and not by the management. 




Figure 3: The Proportion of Labor Force from and out of Uttrakahand (UK) State in Different Capacity Classes (Data Source SIDCUL office, 2010)

The direct economic impact IIE Pantnagar can be seen in terms of 27812 employee monthly salary and government revenues. The employment figure covers about 35 percent of industrial workers in the state. Regardless of the tax concession, during the first stage of formation (2004/5) the state government gross fixed capital increases 71 percent and profits increased by 97 present (India stat, cited in Mittal et al., 2008). This additional income can be used by local governments to meet the expanding needs of their people.

Impact on Local Business and Housing

Although difficult to quantify, the major indirect economic impact is on the local business and housing. Most of the people interviewed, including the key informants, agreed that one of the most discernible impacts of the project has been the increase in local business activities. Market vendors and small sari-pari (clothes) store owner's indicated that when the estate was opened their business volume doubled or tripled because of the influx of new customers. These new customers, according to them, were mostly construction and industries workers. They noted, however, that once construction was finished the volume of their business activities also went down.

The pressure on housing is shown by the increasing commercial housing in the area and the emergence of a new class of houselords who rent houses (1000 - 2000 Rupees) to the incoming population. This makes the current prices of residential lots $(1,000,000-$ 2,000,000 Rupees per hectare) is 3 to 4 times higher than it was before and have been increasing fast as Rudrapur is becoming one of the metropolis cities. The "Metropolis City" housing project which is being developed by the Assotech Supertech (JV) is just in front of the IIE Pantnagar. A third floor resident house is priced at about 3,300,000 Rupees per $93 \mathrm{~m}^{2}$ (1000 square feet) excluding additional service costs.

Without added resources, the rapid increase in population could be a big headache for the concerned local governments. But, is fortunate that the corresponding increase in local government revenues made possible by the entry of the big industries in the estate and other allied service industries inside and outside the 
estate greatly helped the local government officials in meeting the expanding demand for municipal services.

\section{Other Observed Socio-Economic Changes}

The data collected from the sample clearly shows that overall living standard of the families has improved due to IIE Pantnagar project implementation. Following positive changes are noteworthy.

There is significant increase in the proportion of workers in the regular employment, especially with contractors as daily wage earners.

Diversification of income and employment avenues through income generation schemes, towards business and other self employment activities, is taking place and there is improvement in the housing standard.

The quality of health care has also improved due to enhancement of diagnostic hospitals with the introduction of new investment opportunities in Rudrapur town.

Service giving sector in general and those starting small business were happy with the improvement of the local business climate brought about by the influx of new manufacturing and service industries and by the influx of people into the area. But some are quick to cite the problem of rising cost of housing and consumer products, and the need to provide social services to the increasing number of people.
Although, the Industrial Estate is established on government land, some informants cited displacement of families due to labor and land price increase coupled with culture pressure. Those families who are uprooted from their residences due to the residual impact of the industrial estate development are suffering from the loss of their original means of livelihood, mostly farming. However, the cost of land has increased due to the coming of the IIE and families indirectly affected by the project might not have received full and adequate compensation by selling their land.

With rapid increasing population of both Rudrapur and Lalkuan town the influx of 32 percent of the employee and their families from other states will make its contribution. These towns seem experiencing some of the pains of rapid (unplanned) urbanization and the demand for essential social services such as medicine, education and protective services, as well as water and electricity. Even market vendor's and store owners who expressed their satisfaction by increase local business activities also expressed power frailer as constrain for their businesses.

From our study we can be able to identify major issues as: Drivers, Impacts, Pressures, Status and Response (DIPSR) model (Figure 4) showing the key interlinked close and effect dynamics of socioeconomic environment. 


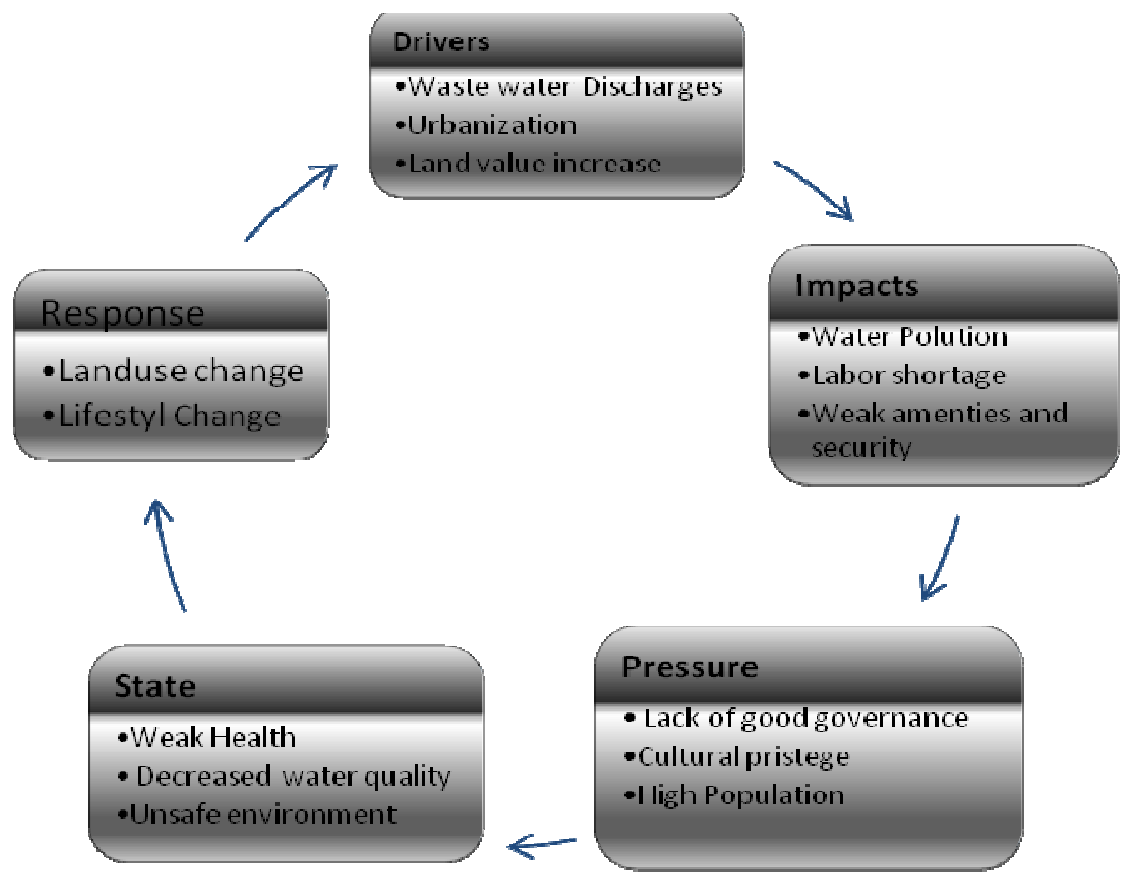

Figure 4: DIPSR diagram of the IIE Pantnagar

As the DIPSR diagram reveals appropriate mitigation, to avert the unexpected consequence of unplanned landuse change and environmental pollution, actions must be focused on releasing the pressure. Thus, we recommend strict monitoring of industrial west disposal; urbanrural land use classification and planning; equitable water and power distribution; and improving infrastructural and security facility, and provision of technical training for the local people.

\section{Conclusions}

From the study it can be concluded that even at its present level of development, the Industrial estate brought about some visible beneficial impacts and drawbacks. There is definite increase in local business activities, local government income, and employment opportunities. Potential residual impacts that would result from the development include increase in population, improved public transport services for the local area, improved landscape and visual amenity, improved recreational opportunities, provision of more varied services and amenities, increased opportunity and scope for future economic investment, and a rise in the value of local land and property. Finally, the proposed mitigations are provision of beneficial infrastructure to the local area, promoting healthier lifestyles, and attracting investment into the local area. This would all contribute to the regeneration of the area.

\section{Acknowledgement}

We acknowledge with gratitude the Ethiopian Embassy in India and G.B. Pant University of Agriculture and Technology (GBPUAT) for sponsorship extended to us for undertaking the study; the State Infrastructure \& Industrial Development Corporation of Uttarakhand Limited (SIDCUL) and Local administrative staff for their assistance and cooperation; and Dr. R. K. Srivastava and Dr. M. E. Ansari of GBPUAT for their professional help. 
Socioeconomic Impact Assessment of Integrated Industrial Estate Pantnagar

ALI et al.

References

Arora, A. and Tiwari, G. (2007). A Handbook for Socio-economic Impact Assessment (SIA) of Future Urban Transport (FUT) Projects, Transportation Research and Injury Prevention Program (TRIPP), Indian Institute of Technology, New Delhi

Asian Development Bank India, (2002). Social Assessment. http://www.adbindia.org/project/II4Soci alAssessment, (Accessed on 10 June, 2010).

District Statistical Diary, (2005). District Udham Singh Nagar. India

Edwards, M. (2009), Community Guide to Development Impact Analysis. http://www.uwes.edu. (Accessed on 01 May, 2010).

Food and Agricultural Organization [FAO]. (2002). Rural development: some issues in the context of the WTO negotiations on agriculture. Rome: FAO.

Grinspun, R. (2003). Exploring the links among global trade, industrial agriculture, and rural underdevelopment. In L.L. North \& J. D. Cameron (Eds.), Rural progress rural decay: a neoliberal adjustment policies and local initiatives, pp. $46-56$. Bloomfield, CT: Kumarian Press, Inc.

Khan, M.K. (2000). Rural poverty in developing countries: issues and polices. IMF Working Papers.

GHK Consulting, UK, (2007), Uttaranchal Urban Development Project (UUDP) Revised Draft Final Report, Volume 6 of 9. Appendices 2-10: Situation Analysis. Asian Development Bank (ADB).
Indian NGOs Pvt Ltd., (2009). Brief About Udham Singh Nagar District. http://www. IndianNGOs.com. (Accessed on 01 May, 2010)

International Association for Impact Assessment (1999). Inter Organizational Committee on Guidelines and Principles for Social Impacts Assessment. http://www.iaia.org/modx/assets/files/P rinciples\%20of\%20IA_web.pdf. (Accessed on July, 2008).

Marafa, L.M. (2002). Socio-ecological impact and risk assessments in the urban environment: a multidisciplinary concept from Hong Kong. The Environmentalist, 22: 377-385.

Mittal, S., Tripathi, G., Sethi, D. (2008). Development Strategy for the Hill Districts of Uttarakhand. Indian Council for Research on International Economic Relations (ICRIER)

Rao, K.S. and Nandy, S.N. (2001). Land Use Pattern and Population Pressure in Uttaranchal, ENVIS Bulletin: Himalayan Ecology \& Development, Volume 9, No. 1.

State Infrastructure \& Industrial Development Corporation of Uttarakhand Ltd. (SIDCUL), (2010a.). IIE Sitarganj - Investors Paradise. http://www.sidcul.com

SIDCUL, (2010b), Details of Employment in the industries, IIE-Pantnagar as of January 2010. Unpublished Data.

Uttaranchal Urban Development Project (UUDP) (2007). Revised Draft Final Report. Volume 6 of 9. Urban Development Department, Government of Uttaranchal, India. 